\title{
Sundar Sarukkai on Indian Higher Education: Quality, Excellence in Neoliberal Times
}

Rolla Das*

Sundar Sarukkai is a philosopher and is currently associated with the National Institute of Advanced Studies, Bangalore as a Professor of Philosophy. His research interests range from philosophy of science, philosophy of mathematics, postmodernism, phenomenology to philosophy of art. A critical philosopher who can, with élan, and a certain sense of analytical rigour, transverse the philosophical terrains between the Western and Indian traditions. He has authored several books, such as Translating the World: Science and Language (2002), Philosophy of Symmetry (2004) and Indian Philosophy and Philosophy of Science (2005). He has earned his doctoral degree from Purdue University, USA following which he has been associated with several institutes such as Indian Institute of Advanced Studies, Manipal University and National Institute of Advanced Studies, Bangalore. He has been the Founder-Director, Manipal Centre for Philosophy and Humanities, Manipal University, Manipal. He can be reached at sarukkai@nias.iisc.ernet.in

\section{Interview with Sundar Sarukkai: An introduction}

This interview primarily focuses on the ideas of instilling a sense of rationality and criticality in higher education. Sundar speaks about the current trends in higher education. He discusses how privatisation and corporatisation is becoming a preferred trajectory for education ventures rather than opening up spaces for

*Christ University, Bengaluru, India; rolla.das@christuniversity.in 
higher learning to explore and reflect upon humanistic values. He asserts that it is extremely important to convince the larger public about the need to be reflective, critical, creative and humane. Unless everyone is made accountable and aware of the responsibilities of education, we might have a system that locks individuals in the world of Chaplin's Modern Times; education, in that world, would be reduced to a skill to create machineindividuals who can operate in well-defined, isolated, mechanised, asocial and an unreflective world. Isolation, he proposes, as a construct is imaginary and worrisome. Individualistic approaches uproot us from our histories of the land and the communities that we belong to.

\section{${ }^{1} R$ D: How can one describe the current educational scenario? What do you think is the future?}

${ }^{2} S S$ : The current scenario is challenging to say the least. Our basic ideas of teaching and learning have changed. The medium of education - I don't mean merely the language as medium - has also drastically changed. The access to information has increased enormously. Although we hoped that by now the access to education would also have become universal, sadly we are nowhere close to reaching this state. In higher education, the Gross Enrollment Ratio is worryingly small. Along with aspiration of more students who want to access education, there is also a deeper question about what education should be. What should our students learn? What would be the content of specialised courses? Or, the skills required for surviving in the world? Or, the skills necessary for jobs and employment? The importance of professional courses meant that all education was becoming professionalised in that it was focussed towards particular specialised skills. Engineering and medicine are becoming only glorified vocational training; so also degrees like BBA and MBA. Therefore, it is not a surprise that in the growing privatisation of everything, including education, the worldviews of private capital influence the nature of education today. Colleges are happy to keep their students happy, which merely translates into giving them

${ }^{1}$ Rolla Das [R D]

2 Sundar Sarukkai (S S] 
degrees as a commodity for the fees paid. The future is going to be more of the same. In India, privatisation of education will increase and will impact public university education. Learning humanistic values, including languages, art and literature, will lose what little importance they have now. The corporatisation of the world will reduce all education to an input with well defined outputs.

\section{$R D$ : Are we able to instill a sense of critical thinking and rationality in our students, which philosophers argue to be of utmost importance to education?}

$S$ S: Our education today does not explicitly attempt to instill a sense of critical thinking and rationality. The view of education today in terms of skills and jobs does not need critical thinking, except beyond that required for doing that skill, being efficient and functional. Critical thinking may itself be a skill but it is one that is not necessarily efficient for a corporatised world. Jobs are increasingly becoming systems where following norms have become extremely important. The ground lost by labour movements will continue in the years to come. So the challenge is to convince the larger society that critical thinking is relevant, useful and applicable to the real world in meaningful ways. More importantly, we have to come to the awareness that unless we teach critical and creative thinking, as well as ways to attain reflective awareness, our future will be under threat. And education can be the primary means to create this awareness.

\section{$R D$ : What is it to instill a sense of criticality and rationality? Can this sensibility be generalised across disciplines?}

$S S$ : The sense of criticality and rationality is not to be equated with some minimalistic idea of logic. Not only is thinking much more complex so is logic itself! To have a sense of criticality can have many elements such as: knowing how we think, understanding the presuppositions in our beliefs and knowledge, being aware of the conditions under which we say something, to become aware of the meaning of what we say and of the concepts that we use, to realise that everything is so interrelated that it would be difficult to truly believe that the individual is the only autonomous being in the world, and so on. Many of these ideas cannot just be taught, they also have to be practiced. This is what good education will do 
when it teaches critical thinking in its broadest sense. To have an awareness of how we use language and concepts, how we convert language to action, how we form our beliefs and so forth, is to be exposed to a broad range of disciplines such as philosophy, history, literature, arts and so on. Without this, even a science student becomes an uncritical practitioner of habits within that community. Since we are cultural, social, historical, and thinking beings, to understand anything we do, it would be necessary to understand something of these forces within us.

$R D$ : People claim that the notion of rationality is western; it is non-neutral in its connotation. Scholars have also opined that rationality is hegemonic and therefore, its predominance is problematic as a virtue. What are your opinions?

$S S$ : The notion of rationality is not western. If rationality is a capacity of the human mind, then to say that it can only belong to 'western' minds seems a bit odd. There can be many theories of rationality and what it is to be rational, and western scholars have written extensively about it. This does not make rationality predominantly western. Indian philosophical traditions, for example, have also produced extremely complex philosophical analysis of inference, decision making and so on. All the systems engage deeply with these questions and they are also quite different from the way rationality was approached within western philosophy. Therefore, it is essential that we understand the structure of rational analysis within systems such as Nyaya, Buddhist and Jaina philosophies, each of which offers complex and deeply analytical modes of understanding rationality. Nonintellectual traditions also essentially engage with rational approaches to their actions. There is a great sense of rational structures even to artistic practices. But, to be able to follow this argument about rationality, it is essential to know more about the nature of concepts, their relation with language and thought and so forth.

\section{$R D$ : What role do higher educational centres of learning have in a democratic nation?}

$S$ S: A most important role. But, it depends on what we would mean by centres of learning. If we mean by that our colleges that 
imprison our bodies and minds, then I would say that they are not really centres of learning at all. Educational institutions today have become centres of giving certificates where learning is incidental. For democratic citizenship to be possible, we need free and enlightened centres of learning. Democracy is impossible without having people exposed to different types of learning, ranging from texts to body practices. You do not need democracy and civilisational values if we want only excellence of a particular kind. China can do a lot without wanting to invest in building democratic values right from student days. Without doubt, its science and technology is far more advanced than India. But, these ways of looking at the world is not one in which social justice, humanitarian values and egalitarianism is possible. We have to decide what kind of a country we want, what kind of a future we imagine and then focus on how we make our educational centres embody these virtues truly. 